\title{
Clinicopathological features and surgical outcomes of neuroendocrine tumors of ampulla of Vater
}

\author{
Kwangho Yang ${ }^{1,2}$, Sung Pil Yun ${ }^{3}$, Suk Kim ${ }^{4}$, Nari Shin ${ }^{5}$, Do Youn Park ${ }^{6}$ and Hyung II Seo ${ }^{3^{*}}$
}

\begin{abstract}
Background: The study aims to investigate the clinicopathological features and surgical outcomes of neuroendocrine tumors of ampulla of Vater (NETAoVs) patients who underwent pancreaticoduodenectomy.

Methods: From January 2007 to December 2014, 45 patients underwent pancreaticoduodenectomy for malignant disease of the ampulla of Vater in our institution. Of those, 5 patients were diagnosed as neuroendocrine tumors. The data included age, sex, presenting symptoms, preoperative imaging, preoperative type of biopsy results, type of operation, pathologic findings and survival status.

Results: The patient's mean age was $55.2 \pm 9.7$ years. Endoscopic ultrasound guided biopsy was performed in 4 patients and gastroduodenoscopic biopsy was performed in one patient. All showed neuroendocrine tumor without mitosis. Mean tumor size was $1.9 \pm 0.56 \mathrm{~cm}$ (range, 1.2-2.0 cm). Lymph node metastases were detected in two patients. All patients were synaptophysin-positive. Median periods of follow-up were 45 months (range, 43-78 months). Recurrence after operation occurred in two patients. 4 patients were alive at the last follow-up.

Conclusions: Radical resection for NETAoVs can provide the information of status of lymph node metastasis after surgery. However, correlation between lymph node metastasis and overall survival is uncertain to date.
\end{abstract}

Keywords: Neoplasms, Neuroendocrine tumors, Ampulla of Vater, Pancreaticoduodenectomy, Treatment outcome

\section{Background}

Neuroendocrine tumors of ampulla of Vater (NETAoVs) are uncommon. To date, only approximately 120 NETAoVs have been described in the literature, most in less 10 cases reports [1-5]. The incidence and prevalence of neuroendocrine tumor seems to have increased in recent years, most likely due to diagnostic technical improvements and endoscopic healthcare surveillance [6].

Computed tomography (CT), magnetic resonance imaging (MRI) and endoscopic ultrasound (EUS) guided biopsy are the main tools for preoperative examinations, but immunohistochemical staining assessment using biopsied specimen is important for diagnosis. There is no standard treatment for NETAoVs, because their natural history and prognostic factors remain unclear. In spite

\footnotetext{
* Correspondence: seohi71@hanmail.net

${ }^{3}$ Department of Surgery, Biomedical Research Institute, Pusan National University Hospital, 179, Gudeok-Ro, Seo-Gu, Busan 602-739, South Korea Full list of author information is available at the end of the article
}

of long term survival has been reported after local excision, many surgeons favor pancreaticoduodenectomy due to the high incidence of lymph node metastasis $[6,7]$. In this study, we report clinicopathological features and surgical outcomes of 5 NETAoVs patients who underwent pancreaticoduodenectomy.

\section{Methods}

From January 2007 to December 2014, 45 patients underwent pancreaticoduodenectomy for malignant disease of the ampulla of Vater in our institution. The surgeries were performed by the same operator. Of those, 5 patients were diagnosed as NETAoVs. The data included age, sex, presenting symptoms, preoperative imaging, preoperative type of biopsy results, type of operation, pathologic findings and survival status. CT and MRI were performed to assess the presence of locoregional lymph node metastases or distant metastases. The pathological data were assessed by the same pathologist, 
according to 2010 World Health Organization (WHO) classification, and 2006 European Neuroendocrine Tumour Society (ENETS) and the seventh edition International Union Against Cancer (UICC) staging systems [8-10] (Table 1). Immunohistochemical analysis included CD56, synaptophysin and chromogranin A expression, and the Ki67 index was assessed for

Table 1 Staging system for neuroendocrine tumor of the ampulla of Vater

\begin{tabular}{|c|c|c|c|c|c|c|c|c|}
\hline \multicolumn{5}{|c|}{ WHO classification (2010) } & \multirow{2}{*}{\multicolumn{4}{|c|}{$\begin{array}{l}<2 \text { mitoses } / 10 \text { HPF and }<3 \% \\
\text { Ki-67 }\end{array}$}} \\
\hline & \multicolumn{4}{|c|}{ Grade 1} & & & & \\
\hline & \multicolumn{4}{|l|}{ Grade 2} & \multicolumn{4}{|c|}{$\begin{array}{l}\text { 2-20 mitoses/10 HPF or 3- } \\
20 \% \mathrm{Ki}-67\end{array}$} \\
\hline & \multicolumn{4}{|l|}{ Grade 3} & \multicolumn{4}{|c|}{$\begin{array}{l}>20 \text { mitoses } / 10 \text { HPF or }>20 \% \\
\text { Ki-67 }\end{array}$} \\
\hline \multicolumn{9}{|c|}{ TNM staging system } \\
\hline & \multicolumn{4}{|c|}{ ENETS (2006) } & \multicolumn{4}{|c|}{ UICC (7th edition, 2009) } \\
\hline \multicolumn{9}{|c|}{$T$ - primary tumor } \\
\hline Tx & \multicolumn{8}{|c|}{$\begin{array}{l}\text { Primary tumour cannot be } \\
\text { assessed }\end{array}$} \\
\hline T0 & \multicolumn{8}{|c|}{$\begin{array}{l}\text { No evidence of primary } \\
\text { tumour }\end{array}$} \\
\hline $\mathrm{T} 1$ & \multicolumn{4}{|c|}{$\begin{array}{l}\text { Invasion of lamina propria or } \\
\text { submucosa and size } \leq 1 \mathrm{~cm}\end{array}$} & \multicolumn{4}{|c|}{$\begin{array}{l}\text { Limited to ampulla of Vater or } \\
\text { sphincter of Oddi }\end{array}$} \\
\hline $\mathrm{T} 2$ & \multicolumn{4}{|c|}{$\begin{array}{l}\text { Invasion of muscularis propria } \\
\text { or size }>1 \mathrm{~cm}\end{array}$} & \multicolumn{4}{|c|}{$\begin{array}{l}\text { Invasion of the duodenum } \\
\text { wall }\end{array}$} \\
\hline T3 & \multicolumn{4}{|c|}{$\begin{array}{l}\text { Invasion of the pancreas or } \\
\text { retroperitoneum }\end{array}$} & \multicolumn{4}{|c|}{ Invasion of the pancreas } \\
\hline $\mathrm{T} 4$ & \multicolumn{4}{|c|}{$\begin{array}{l}\text { Invasion of the peritoneum or } \\
\text { other organs }\end{array}$} & \multicolumn{4}{|c|}{$\begin{array}{l}\text { Invasion in peripancreatic soft } \\
\text { tissues or other adjacent } \\
\text { organs or structures }\end{array}$} \\
\hline \multicolumn{9}{|c|}{$N$ - regional lymph nodes } \\
\hline $\mathrm{Nx}$ & \multicolumn{8}{|c|}{$\begin{array}{l}\text { Regional lymph nodes cannot } \\
\text { be assessed }\end{array}$} \\
\hline No & \multicolumn{8}{|c|}{$\begin{array}{l}\text { No regional lymph node } \\
\text { metastasis }\end{array}$} \\
\hline N1 & \multicolumn{8}{|c|}{$\begin{array}{l}\text { Regional lymph node } \\
\text { metastasis present }\end{array}$} \\
\hline \multicolumn{9}{|c|}{$M$ - distant metastasis } \\
\hline$M x$ & \multicolumn{8}{|c|}{$\begin{array}{l}\text { Distant metastasis cannot be } \\
\text { assessed }\end{array}$} \\
\hline Mo & \multicolumn{8}{|c|}{ No distant metastasis } \\
\hline M1 & \multicolumn{8}{|c|}{ Distant metastasis present } \\
\hline \multirow[t]{6}{*}{ Staging } & Stage I & $\mathrm{T} 1$ & No & MO & Stage la & $\mathrm{T} 1$ & No & Mo \\
\hline & Stage Ila & $\mathrm{T} 2$ & NO & MO & Stage Ib & $\mathrm{T} 2$ & No & Mo \\
\hline & Stage IIb & $\mathrm{T} 3$ & No & MO & Stage lla & $\mathrm{T} 3$ & No & Mo \\
\hline & Stage IIla & $\mathrm{T} 4$ & No & MO & Stage Ilb & $\mathrm{T} 1-3$ & N1 & Mo \\
\hline & Stage IIIb & Any $T$ & N1 & MO & Stage III & $\mathrm{T} 4$ & Any N & Mo \\
\hline & Stage IV & Any $T$ & Any N & M1 & Stage IV & Any $T^{\prime}$ & Any N & M1 \\
\hline
\end{tabular}

ENETS European Neuroendocrine Tumour Society staging system, HPF high power fields, UICC International Union Against Cancer staging system, WHO World Health Organisation classification histological grading. The study was reviewed and approved by the Pusan National University Hospital Institutional Review Board.

\section{Results}

\section{Clinical findings and preoperative evaluation}

The clinical features of the 5 patients are listed in Table 2 . Mean age was $55.2 \pm 9.7$ years (range, 36-62 years) and the male to female ratio was 3:2. One patient presented with obstructive jaundice, which led to endoscopic retrograde cholangiopancreatography. In 4 patients, the tumor was discovered during gastroduodenoscopy as part of a regular medical check-up. No patient had specific neuroendocrine symptoms, and signs of Recklinghausen's disease or Zollinger-Ellison syndrome [11, 12]. EUS-guided biopsy was performed in 4 patients and gastroduodenoscopic biopsy was performed in one patient. Histologically, all cases displayed neuroendocrine tumor without mitosis.

CT scan using a hepatopancreatic protocol was performed in all patients and MRI was performed in 3 patients. The imaging procedures showed an enhanced mural or intramural mass. Only one patient showed dilatation of main pancreatic duct in imaging study. Liver metastases were not detected in any patient. Positron emission tomography-CT performed in 4 patients showed fluorodeoxyglucose uptake in all the patients (mean SUVmax 4.2, range; 2.5-7).

\section{Treatment}

Three patients underwent pylorus-preserving pancreaticoduodenectomy. The other two patients underwent conventional pancreaticoduodenectomy because severe adhesion between stomach and pancreas, and tumor invasion to duodenal first portion, respectively. Lymph node dissection was performed as standard extent for pancreas cancer. Duct-to-mucosa Pancreaticojejunostomy was performed in every case. There was no mortality. There were three minor complications (grade I or II according to Clavien-Dindo classification) including 2 delayed gastric emptying and a pancreas fistulae grade A. No patient was treated by radiological intervention or re-exploration. After surgery, adjuvant chemotherapy using etoposide-cisplatin intravenous administration with or without octreotide LAR intramuscular injection was done in 4 patients. Distant recurrence of NETAoVs occurred in 2 patients (case 2 and case 5). Case 2 suffered single liver metastasis at 10 months after surgery and underwent radiofrequency ablation for the lesion followed by chemotherapy with etoposide-cisplatin. However, multiple liver metastases still occurred and the patient expired at 67 months after surgery. Case 5 had multiple liver metastases at 11 months after surgery. This patient underwent chemotherapy with sunitinib and complete remission was achieved. 
Table 2 Clinical features and outcomes of patients

\begin{tabular}{|c|c|c|c|c|c|c|c|c|c|c|}
\hline Case & Sex & Age range & Symptom & $\begin{array}{l}\mathrm{L} / \mathrm{N} \\
\text { ratio }\end{array}$ & $\begin{array}{l}\text { Biopsy } \\
\text { result }\end{array}$ & Operation & Adjuvant CTx & Recurrence site & $\begin{array}{l}\text { Treatment } \\
\text { for recurrence }\end{array}$ & $\begin{array}{l}\text { Survival } \\
\text { outcome }\end{array}$ \\
\hline 1 & Female & $50-59$ & Incidental & $62.1 \%$ & NET & PPPD & Yes & NED & & $\begin{array}{l}78 \text { months } \\
\text { alive }\end{array}$ \\
\hline 2 & Male & $60-69$ & Jaundice & $15.8 \%$ & NET & PPPD & Yes & Liver & RFA, CTx & $\begin{array}{l}67 \text { months } \\
\text { dead }\end{array}$ \\
\hline 3 & Female & $50-59$ & Incidental & $40.9 \%$ & NET & PPPD & Yes & NED & & $\begin{array}{l}45 \text { months } \\
\text { alive }\end{array}$ \\
\hline 4 & Male & $30-39$ & Incidental & $52.7 \%$ & NET & PD & Yes & NED & & $\begin{array}{l}44 \text { months } \\
\text { alive }\end{array}$ \\
\hline 5 & Male & $60-69$ & Incidental & $23.4 \%$ & NET & PD & No & liver & $C T x$ & $\begin{array}{l}43 \text { months } \\
\text { alive }\end{array}$ \\
\hline
\end{tabular}

CTx chemotherapy, L/N ratio lymphocyte/neutrophil ratio, NED no evidence of disease, NET neuroendocrine tumor, $P D$ pancreaticoduodenectomy, $P P P D$ pylorus preserving pancreaticoduodenectomy, RFA radiofrequency ablation

\section{Pathology}

All patients underwent R0 resection, which was defined as no residual tumor with negative surgical margin. The mean tumor size was $1.9 \pm 0.56 \mathrm{~cm}$ (range, $1.2-2.0 \mathrm{~cm}$ ). Lymph node metastases were detected in two patients. All patients were synaptophysin-positive, 2 were chromogranin-positive and 5 were CD56-positive. Lymphovascular invasion was observed in 3 patients and there was no perineural invasion in all patients. In case 2, the histological result was collision tumor accompanied with poorly differentiated neuroendocrine carcinoma at the deepest invasive portion and well differentiated adenocarcinoma at superficial portion (pT3). Neuroendocrine carcinoma accounted for $90 \%$ of the tumor mass, and adenocarcinoma 10\% (Fig. 1). In this patient, liver metastases were confirmed as neuroendocrine tumor by needle biopsy 10 months after surgery. The immunohistochemical data of the 5 patients and tumor assessments according to the staging system are listed in Table 3.

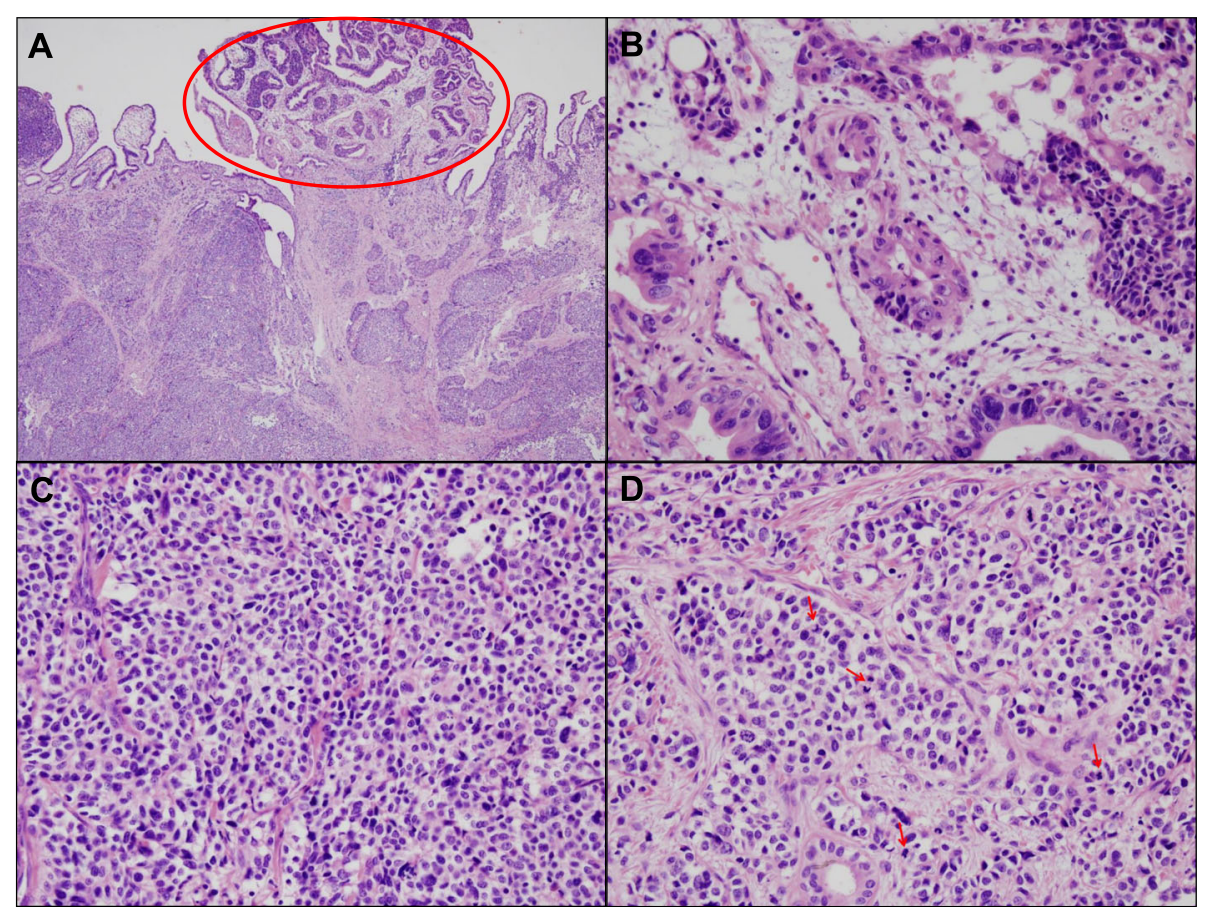

Fig. 1 Pathologic findings of collision tumor accompanied with neuroendocrine carcinoma and adenocarcinoma. a Red circle: adenocarcinoma, well-differentiated area. Tumor cells forming gland and showing infiltrative growth. Under area: solid tumor cell nest (H\&E stain, $\times 40)$. b High power view of adenocarcinoma area (H\&E stain, $\times 400$ ). Atypical epithelial cells forming gland. c High power view of solid nest area (H\&E stain, $\times 400)$. The tumor cell showing typical "salt and pepper" chromatin pattern which is compatible with neuroendocrine tumor cells. They are positive for neuroendocrine marker, synaptophysin and chromogranin in immunohistochemistry staining. $\mathbf{d}$ The neuroendocrine tumor area showing increased mitosis (red arrow), and increased Ki-67 index (about 70\%) (H\&E stain, $\times 400)$ 
Table 3 Histopathological and immunohistochemical data and staging

\begin{tabular}{|c|c|c|c|c|c|c|c|c|c|}
\hline Case & $\begin{array}{l}\text { Size } \\
(\mathrm{cm})\end{array}$ & $\begin{array}{l}\text { Lymph node } \\
\text { metastasis }(\mathrm{n})\end{array}$ & $\begin{array}{l}\text { Mitosis } \\
\text { (/10HPF) }\end{array}$ & $\begin{array}{l}\text { Ki-67 } \\
(\%)\end{array}$ & $\begin{array}{l}\text { Lymphovascular } \\
\text { invasion }\end{array}$ & $\begin{array}{l}\text { Perineural } \\
\text { invasion }\end{array}$ & WHO & ENETS & UICC \\
\hline 1 & 2.2 & No (0/12) & 1 & 1 & Yes & No & G1 & $\| \mathrm{A}$ & IA \\
\hline 2 & 1.2 & No $(0 / 20)$ & 102 & 70 & Yes & No & G3 & $\| B$ & $\| \mathrm{A}$ \\
\hline 3 & 1.5 & Yes $(1 / 17)$ & 5 & 3 & No & No & G2 & $\| I B$ & $\| B$ \\
\hline 4 & 2.6 & Yes (4/20) & 4 & 4 & Yes & No & G2 & $\| I B$ & $\| B$ \\
\hline 5 & 2.0 & No $(0 / 50)$ & 1 & 5 & No & No & $\mathrm{G} 2$ & $\| \mathrm{A}$ & IB \\
\hline
\end{tabular}

ENETS European Neuroendocrine Tumour Society, UICC International Union Against Cancer, WHO World Health Organization

\section{Survival}

Median periods of follow-up were 45 months (range, 43-78 months), and complete follow-up data were available for all patients. Laboratory test and abdominal CT scan were performed every 3 months in the first 2 years after operation, and then every 6 months. Chest CT scan was performed once in a year to identify distant metastasis. 4 patients were alive at the last follow-up. Recurrence in the liver was observed in 2 patients. In these two patients, the Ki-67 index exceeded 5\% and a low lymphocyte-neutrophil ratio was observed when compared to the other 3 patients $(23.4 \%$ and $15.8 \%$ versus $52.7 \%, 40.9 \%$ and $62.1 \%$ ).

\section{Discussion}

The small bowel is most common site of neuroendocrine tumor occur, however, neuroendocrine tumor very rarely occurs at the ampulla of Vater [13]. Neuroendocrine tumors originating in the duodenum represent merely $4 \%$ of all carcinoid tumors [14]. In the previous study of Randle et al., the proportion of neuroendocrine tumors from duodenum and ampulla of Vater were $92 \%$ and $8 \%$, respectively [15]. The common clinical feature is jaundice, similar to other ampullary tumors. In some cases, patients complain of non-specific gastrointestinal symptoms $[2,5,16]$. In the latter, it is difficult to detect an ampulla of Vater tumor without performing endoscopy or other imaging studies. In the present study, these tumors were detecting during gastroduodenoscopy of medical check-up in 4 of 5 patients; the remaining patient had jaundice.

The diagnostic modalities for NETAoVs are same as those for ampullary adenocarcinoma. CT or MRI can reveal NETAoVs as a mural and intramural enhancing mass within the submucosal region [17]. For definite diagnosis, immunohistochemical staining is needed after tumor biopsy. Because of the finding of a submucosal tumor at the ampulla on endoscopy, the rate of preoperative histological diagnosis on endoscopic biopsy is low, ranging from 14 to $66 \%[2,5,13,18]$. In the present study, a correct diagnosis of NETAoVs without symptoms was confirmed preoperatively in 4 patients for a preoperative diagnostic accuracy of $100 \%$; the excellent results reflected the use of EUS-guided biopsy.
Therefore, EUS-guided biopsy is considered to be more useful than endoscopic biopsy alone in obtaining a preoperative accurate diagnosis [16]. However, mitosis count of biopsy specimen is an incorrect assessment at present, and requires refinement.

Previous studies reported that the incidence of lymph node metastases approaches $50 \%$, which has led to the recommendation of pancreaticoduodenectomy as the procedure of choice for NETAoVs [5, 6, 13, 19-21]. Nodal involvement appears to be of lesser significance to long-term survival $[5,6,16,22,23]$. Because a more advanced stage does not predict a worse prognosis, the TNM and ENETS staging systems are limited in predicting prognosis. If lymph node metastasis is not a prognostic factor, endoscopic local resection or surgical ampullectomy might be available treatment options for selective patients with NETAoVs [2, 24, 25]. Although less radical operation may decrease postoperative complication rate and preserve pancreatic function, it has the risk of incomplete removal of metastatic lymph nodes [26]. Therefore, ampullectomy can be considered for the patients with well differentiated, slow-growing and small sized tumors, who cannot be tolerable for radical operation due to high surgical risk [5].

In this series, all the patients underwent pancreaticoduodenectomy. Lymph node metastasis occurred in 2 cases; both patients remain alive without recurrence. Under the WHO classification system, our cases consisted of one neuroendocrine tumor, 3 well differentiated neuroendocrine carcinomas and one poorly differentiated neuroendocrine carcinoma. Under the TNM staging system, we had two stage I, and three stage II. Under the ENETS system, we had three stage II, and two stage III. In this study, the Ki-67 index was 5 and $70 \%$ in two cases of liver metastases. Although it is difficult to downplay the importance of the Ki-67 index in neuroendocrine tumors, further research is needed for the prognostic significance of the Ki-67 index. Low lymphocyte/ neutrophil ratio is a factor reducing disease-free survival [27]. In this study, low lymphocyte/neutrophil ratio appeared to be associated with early recurrence. However, due to the limited number of patients, statistical significance was doubtful. 
There is no consensus regarding adjuvant treatment for NETAoVs. We have performed adjuvant chemotherapy for the patients who had lymphovascular invasion or lymph node. As a result, adjuvant chemotherapy was performed in 4 patients in this study. One patient among them and a patient without adjuvant chemotherapy experienced recurrence.

\section{Conclusions}

In conclusion, radical resection for NETAoVs can provide the information of status of lymph node metastasis after surgery. In present study, two of the five patients developed liver metastases within a year despite implementation of radical resection with lymph node dissection. This result suggests high aggressiveness of NETAoVs. However, correlation between lymph node metastasis and overall survival is uncertain to date due to lack of the number of NETAoVs. Regular medical check-up including gastroduodenoscopy may give a chance to detect and cure asymptomatic NETAoVs.

\section{Abbreviations}

CT: Computed tomography; EUS: Endoscopic ultrasound; MRI: Magnetic resonance imaging; NETAoV: Neuroendocrine tumors of ampulla of Vater

\section{Acknowledgements}

Not applicable.

\section{Funding}

This research received no specific grant.

\section{Availability of data and materials}

The datasets used during the current study available from the corresponding author on reasonable request.

\section{Authors' contributions}

$\mathrm{KY}$ performed data acquisition, analysis and interpretation of data, and drafted the manuscript; KY, SPY and HIS participated in the concept and design of the study; SK, NS and DYP supervised the manuscript for important intellectual content; $\mathrm{KY}$ and HIS critically revised the manuscript for important intellectual content. All authors read and approved the final manuscript.

\section{Competing interests}

The authors declare that they have no competing interests.

\section{Consent for publication}

Not applicable.

\section{Ethics approval and consent to participate}

The study was reviewed and approved by the Pusan National University Hospital Institutional Review Board. Written informed consent was obtained from all patients.

\section{Publisher's Note}

Springer Nature remains neutral with regard to jurisdictional claims in published maps and institutional affiliations.

\section{Author details}

${ }^{1}$ Department of Surgery, Division of Hepato-Biliary-Pancreatic Surgery and Transplantation, Pusan National University Yangsan Hospital, 20, Geumo-ro, Mulgeum-eup, Yangsan, Gyeongsangnam-do 50612, South Korea. ${ }^{2}$ Research Institute for Convergence of Biomedical Science and Technology, Pusan National University Yangsan Hospital, 20, Geumo-ro, Mulgeum-eup, Yangsan, Gyeongsangnam-do 50612, South Korea. ${ }^{3}$ Department of Surgery, Biomedical
Research Institute, Pusan National University Hospital, 179, Gudeok-Ro, Seo-Gu, Busan 602-739, South Korea. ${ }^{4}$ Department of Radiology, Biomedical Research Institute, Pusan National University Hospital, 179, Gudeok-Ro, Seo-Gu, Busan 602-739, South Korea. ${ }^{5}$ Department of Pathology, Pusan National University Yangsan Hospital, 20, Geumo-ro, Mulgeum-eup, Yangsan, Gyeongsangnam-do 50612, South Korea. ${ }^{6}$ Department of Pathology, Biomedical Research Institute, Pusan National University Hospital, 179, Gudeok-Ro, Seo-Gu, Busan 602-739, South Korea.

Received: 16 November 2016 Accepted: 23 May 2017

Published online: 31 May 2017

\section{References}

1. Hatzitheoklitos E, Büchler MW, Friess H, Poch B, Ebert M, Mohr W, et al. Carcinoid of the ampulla of vater. Clinical characteristics and morphologic features. Cancer. 1994;73:1580-8.

2. Hartel M, Wente MN, Sido B, Friess H, Büchler MW. Carcinoid of the ampulla of Vater. J Gastroenterol Hepatol. 2005;20:676-81.

3. Waisberg J, Matos LLD, Waisberg DR, Santos HVBD, Fernezlian SM, Capelozzi VL. Carcinoid of the minor duodenal papilla associated with pancreas divisum: case report and review of the literature. Clinics. 2006;61:365-8.

4. Emory RE Jr, Emory TS, Goellner JR, Grant CS, Nagorney DM. Neuroendocrine ampullary tumors: spectrum of disease including the first report of a neuroendocrine carcinoma of non-small cell type. Surgery. 1994;115:762-6.

5. Carter JT, Grenert JP, Rubenstein L, Stewart L, Way LW. Neuroendocrine tumors of the ampulla of Vater: biological behavior and surgical management. Arch Surg. 2009;144:527-31.

6. Dumitrascu T, Dima S, Herlea V, Tomulescu V, lonescu M, Popescu I. Neuroendocrine tumours of the ampulla of Vater: clinico-pathological features, surgical approach and assessment of prognosis. Langenbeck's Arch Surg. 2012; 397:933-43.

7. Nikfarjam M, McLean C, Muralidharan V, Christophi C. Neuroendocrine tumours of the ampulla of Vater. ANZ J Surg. 2002;72:531-3.

8. Bosman FT, Carneiro F, Hruban RH, Theise ND. WHO classification of tumours of the digestive system: World Health Organization, 2010.

9. Rindi G, Klöppel G, Alhman H, Caplin M, Couvelard A, de Herder WW, et al. TNM staging of foregut (neuro) endocrine tumors: a consensus proposal including a grading system. Virchows Arch. 2006;449:395-401.

10. Sobin $L H$, Gospodarowicz MK, Wittekind C. International Union Against Cancer. TNM Classification of Malignant Tumours. 7th ed. Oxford: WileyBlackwell; 2009

11. Mayoral W, Salcedo J, Al-Kawas F. Ampullary carcinoid tumor presenting as acute pancreatitis in a patient with von Recklinghausen's disease: case report and review of the literature. Endoscopy. 2003;35:854-7.

12. Åkerström G. Management of carcinoid tumors of the stomach, duodenum, and pancreas. World J Surg. 1996;20:173-82.

13. Hwang S, Lee SG, Lee YJ, Han DJ, Kim SC, Kwon SH, et al. Radical surgical resection for carcinoid tumors of the ampulla. J Gastrointest Surg. 2008;12:713-7.

14. Yao JC, Hassan M, Phan A, Dagohoy C, Leary C, Mares JE, et al. One hundred years after "carcinoid": epidemiology of and prognostic factors for neuroendocrine tumors in 35,825 cases in the United States. J Clin Oncol. 2008;26:3063-72.

15. Randle RW, Ahmed S, Newman NA, Clark CJ. Clinical outcomes for neuroendocrine tumors of the duodenum and ampulla of Vater: a population-based study. J Gastrointest Surg. 2014;18:354-62.

16. Jayant M, Punia R, Kaushik R, Sharma R, Sachdev A, Nadkarni NK, et al. Neuroendocrine Tumors of the Ampulla of Vater: Presentation, Pathology and Prognosis. JOP. 2012;13:263-7.

17. Yano F, Hama Y, Abe K, Iwasaki Y, Hatsuse K, Kusano S. Carcinoid tumor of the ampulla of Vater: Magnetic resonance imaging findings. Clin Imaging. 2005;29:207-10.

18. Kim J, Lee WJ, Lee SH, Lee KB, Ryu JK, Kim YT, et al. Clinical features of 20 patients with curatively resected biliary neuroendocrine tumours. Dig Liver Dis. 2011:43:965-70.

19. Albores-Saavedra J, Hart A, Chablé-Montero F, Henson DE. Carcinoids and high-grade neuroendocrine carcinomas of the ampulla of vater: a comparative analysis of 139 cases from the surveillance, epidemiology, and end results program-a population based study. Arch Pathol Lab Med. 2010; 134:1692-6. 
20. Cokmert S, Demir L, Akder Sari A, Kucukzeybek Y, Can A, Akyol M, et al. Synchronous Appearance of a High-Grade Neuroendocrine Carcinoma of the Ampulla Vater and Sigmoid Colon Adenocarcinoma. Case reports in oncological medicine. 2013:2013:4. Article ID 930359. http://dx.doi.org/10. 1155/2013/930359.

21. Selvakumar E, Rajendran S, Balachandar TG, Kannan DG, Jeswanth S, Ravichandran P, et al. Neuroendocrine carcinoma of the ampulla of Vater: a clinicopathologic evaluation. Hepatobiliary Pancreat Dis Int. 2008;7:422-5.

22. Pyun DK, Han JM, Lee SS, Kim MH, Lee SS, Seo DW, et al. Case Reports: A Carcinoid Tumor of the Ampulla of Vater Treated by Endoscopic Snare Papillectomy. Korean J. Intern. Med. 2004;19:257-60.

23. Sakka N, Smith RA, Whelan P, Ghaneh P, Sutton R, Raraty M, et al. A preoperative prognostic score for resected pancreatic and periampullary neuroendocrine tumours. Pancreatology. 2009;9:670-6.

24. Rattner DW, CF-d C, Brugge WR, Warshaw AL. Defining the criteria for loca resection of ampullary neoplasms. Arch Surg. 1996;131:366-71.

25. Salmi S, Ezzedine S, Vitton V, Ménard C, Gonzales JM, Desjeux A, et al. Can papillary carcinomas be treated by endoscopic ampullectomy? Surg Endosc. 2012:26:920-5

26. Krishna SG, Lamps LW, Rego RF. Ampullary carcinoid: diagnostic challenges and update on management. Clin Gastroenterol Hepatol. 2010;8:e5-6.

27. Garcea G, Ladwa N, Neal C, Metcalfe MS, Dennison AR, Berry DP. Preoperative neutrophil-to-lymphocyte ratio (NLR) is associated with reduced disease-free survival following curative resection of pancreatic adenocarcinoma. World J Surg. 2011;35:868-72.

\section{Submit your next manuscript to BioMed Central and we will help you at every step:}

- We accept pre-submission inquiries

- Our selector tool helps you to find the most relevant journal

- We provide round the clock customer support

- Convenient online submission

- Thorough peer review

- Inclusion in PubMed and all major indexing services

- Maximum visibility for your research

Submit your manuscript at www.biomedcentral.com/submit

) Biomed Central 